\title{
ESTUDO ULTRAESTRUTURAL DA ESPERMATOGÊNESE DE DONAX STRIATUS LINNAEUS (MOLLUSCA, BIVALVIA) DO LITORAL NORTE DO BRASIL
}

\author{
E. Matos ${ }^{1}$ \\ P. Matos ${ }^{2}$ \\ L. Corral ${ }^{3}$ \\ C. Azevedo ${ }^{3}$
}

\begin{abstract}
ULTRASTRUCTURAL STUDY OF THE SPERMATOGENESIS OF DONAX STRLATUS Linnaeus (Mollusca, Bivalvia) from Brazil Northern littoral. The fine structure of the sperm and spermatogenesis of the Donax striatus are described. The morphology of the spermatozoa is classified as of a primitive type with a head, mid-piece with four mitochondria and tail. The head shows a complex acrosome, typical of heterodont bivalves. During spermatogenesis the nuclear chromatin shows granular condensation. The present paper describes detailed observations of the espermatozoa.

KEY WORDS. Ultrastructure, Spermatozoa, Mollusca Bivalvia
\end{abstract}

Os bivalves do gênero Donax são habitantes comuns do sedimento marinho de região temperada e tropical do mundo (ANSELL 1983). Donax striatus é membro da macrofauna do litoral norte do Brasil. A importância deste animal no ecossistema de areias de praia é pouco conhecida, e principlamente sobre o ciclo reprodutivo, onde poucos trabalhos são encontrados no gênero Donax (DE VILLIERS 1975; MCLACHLAN \& HANEKOM 1979; MCLACHLAN \& VAN DER HORST 1979; HODGSON et al. 1990). Neste trabalho apresenta-se a primeira descrição da estrutura do espermatozóide e espermatogênese do molusco bivalve Donax striatus no litoral norte do Brasil.

\section{MATERIAL E MÉTODOS}

Animais foram coletados nas praias de Ajuruteua $\left(00^{\circ} 50^{\prime} 55^{\prime \prime} \mathrm{S}\right.$ e $46^{\circ} 36^{\prime}$ 30 "W) e Salinópolis $\left(00^{\circ} 36^{\prime} 47^{\prime \prime S}\right.$ e $\left.47^{\circ} 21^{\prime} 30^{\prime \prime W}\right)$ e transportados para Belém, onde no laboratório foram retiradas as gônadas e preparadas para microscopia óptica e eletrônica. Os fragmentos de testículos foram retirados imediatamente,

1) Departamento de Biologia Animal - Histologia e Embriologia, Faculdade de Ciências Agrárias do Pará, Av. Tancredo Neves, 66077-530 Belém, Pará, Brasil.

2) Departamento de Histologia e Embriologia, Universidade Federal do Pará, 66059-900 Belém, Pará, Brasil.

3) Departamento do Biologia Celular, IMAR-Instituto do Mar, Universidade do Porto-Portugal, 4000 Porto, Portugal. 

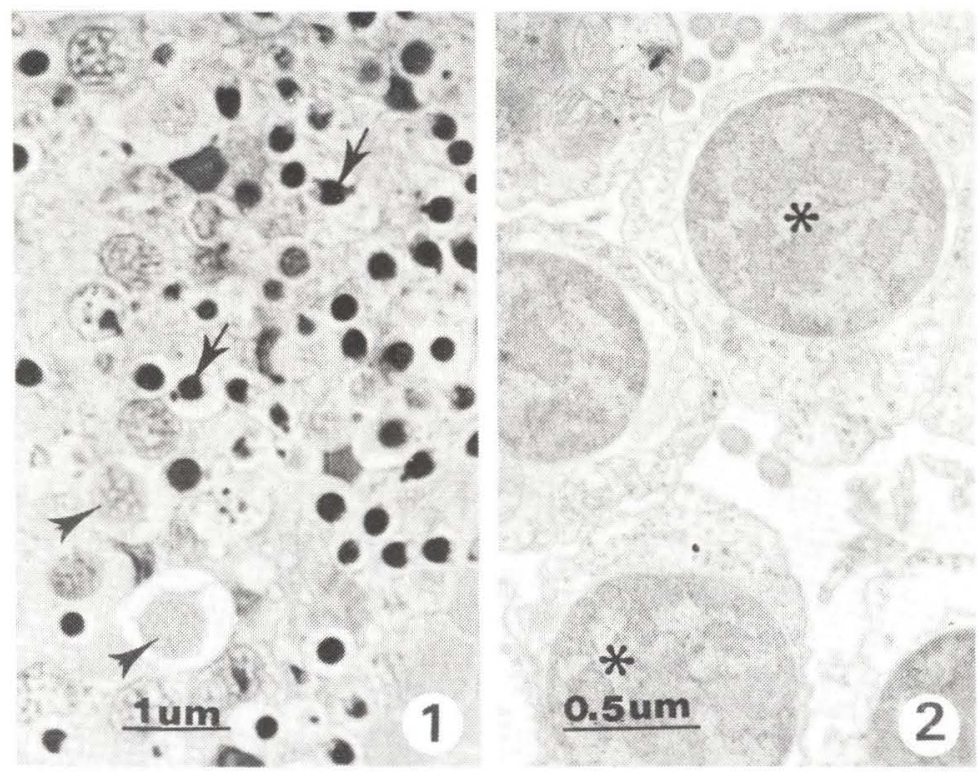

Figs 1-2. (1) Corte semifino do testículo de Donax striatus - células germinativas são observadas variando o estágio de desenvolvimento - células iniciais (cabeças de setas), espermatozóides (setas); (2) grupo de espermatócitos $\left(^{*}\right)$ em início da fase de espermiogênese.

confirmados em MO, e fixados para microscopia eletrônica, em glutaraldeído a $3 \%$ tamponado com cacodilato de sódio a $0,2 \mathrm{M}, \mathrm{pH} 7,4$ durante três horas a $4^{\circ} \mathrm{C}$. Depois de lavados no mesmo tampão, durante duas horas a $4^{\circ} \mathrm{C}$, os fragmentos foram pós-fixados, durante duas horas a $4^{\circ} \mathrm{C}$, em tetróxido de ósmio a $2 \%$ devidamente tamponado. Sequencialmente os fragmentos foram desidratados em série crescente de álcool, seguida de três passagens em óxido de propileno. Depois de bem desidratado o material foi incluído em Durcupan (Matos et al. 1993). As observações foram feitas em cortes semifinos, e em cortes ultrafinos contrastados com acetato de uranila e citrato de chumbo, em microscópio eletrônico JEOL $100 \mathrm{CXII}$ operando a $60 \mathrm{Kv}$.

\section{RESULTADOS}

Em corte semifino observamos as espermatogonias localizadas perifericamente e os espermatozóides maduros caminham para a região central dos lobos testiculares (Fig. 1).

Espermatogênese: o processo de espermatogênese é semelhante ao de $D$. serra Dillwin, 1817, D. sordidus Hanley, 1845 e D. madagascariensis Wood, 1828, entretanto uma simples descrição é necessária, pois as espermatogonias localizam-se na base dos lobos testiculares e as células espermáticas maduras estão deslocadas para o centro dos mesmos. 
As espermatogonias estão caracterizadas por um núcleo arredondado com o nucléolo proeminete, eletrodenso. O núcleo apresenta pequenos grumos de cromatina associado a membrana nuclear. O citoplasma de todas as espermatogonias contém numerosas mitocôndrias, ribossomas livres e pequenas regiões de retículo endoplasmático rugoso.
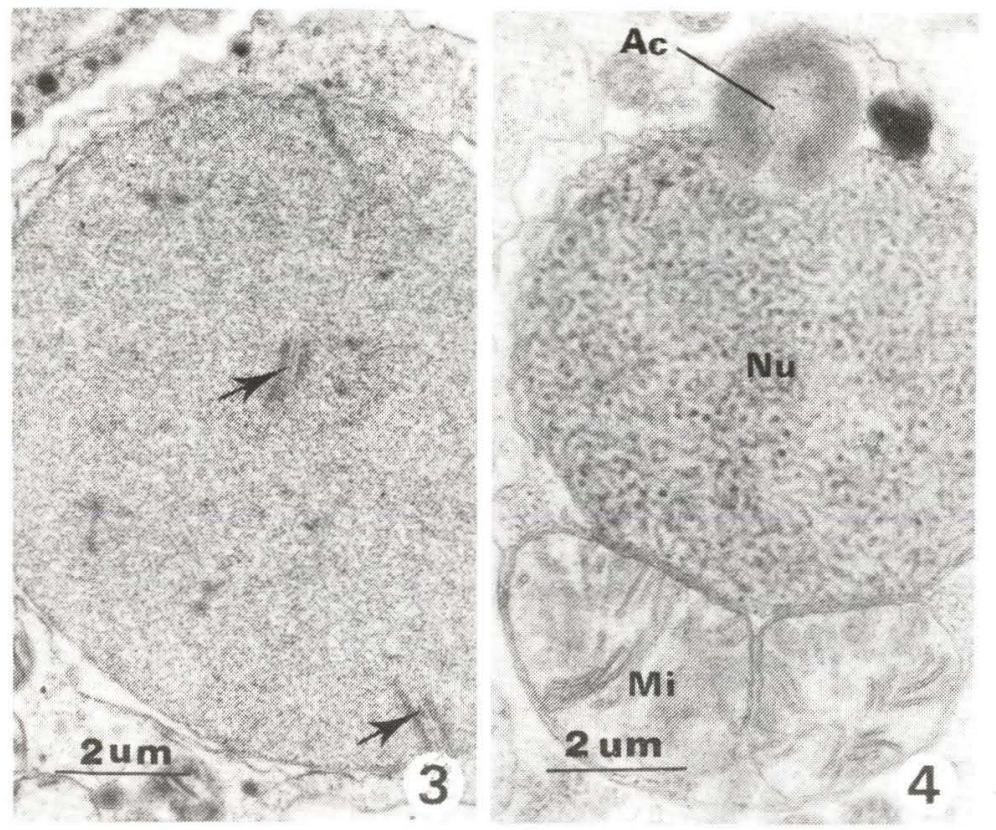

Figs 3-4. (3) Eletromicrografia de pormenor ultraestrutural de espermatócito em zigóteno - complexo sinaptonêmicos (setas); (4) aspecto logitudinal de espermátide - acrosoma (Ac), núcleo (Nu), mitocôndria (Mi).

Os espermatócitos apresentam núcleo ligeiramente achatado, sem evidenciação nuclear, e cromatina mais dispersa (Fig. 2). Podemos observar complexos sinaptonêmicos (Fig. 3). O citoplasma apresenta formações eletrodensas, membrana de complexo pró-acrosomal.

As espermatides apresentam núcleo arredondado e que progressivamente para atingir a fase final de maturação, sofre pequena modificação para ovóide achatado, com modificação de arrumação de cromatina nuclear, inicialmente uma cromatina nuclear esférica. Observa-se também a iniciação de uma vesícula pré-acrosomal (Fig. 4).

O espermatozóide apresenta núcleo achatado e na região anterior ao complexo acrosomal está localizada a fossa nuclear ou fossa acrosomal (Figs 5-6).

O acrosoma de Donax striatus é cônico, comprimindo duas regiões de diferentes eletrodensidades. A porção anterior e central é radiolúcida e a porção basal é radiopaca, aparentando apresentar espaços lamelares. Internamente três 
regiões podem ser reconhecidas: uma região anterior radiolúcida restrita a esta região e a maior parte do material acrosomico é mais eletrodenso e dividido em duas distintas áreas morfologicamente (Figs 6-7).

A peça intermediária corresponde a 4 mitocôndrias esféricas com numerosas cristas bem desenvolvidas (Fig. 6). No centro da ponte mitocondrial observamos os centríolos proximal e distal (Fig. 7). A cauda com o normal arranjo de $9 p+2$ microtubulos emerge do centríolo distal (Fig. 7).

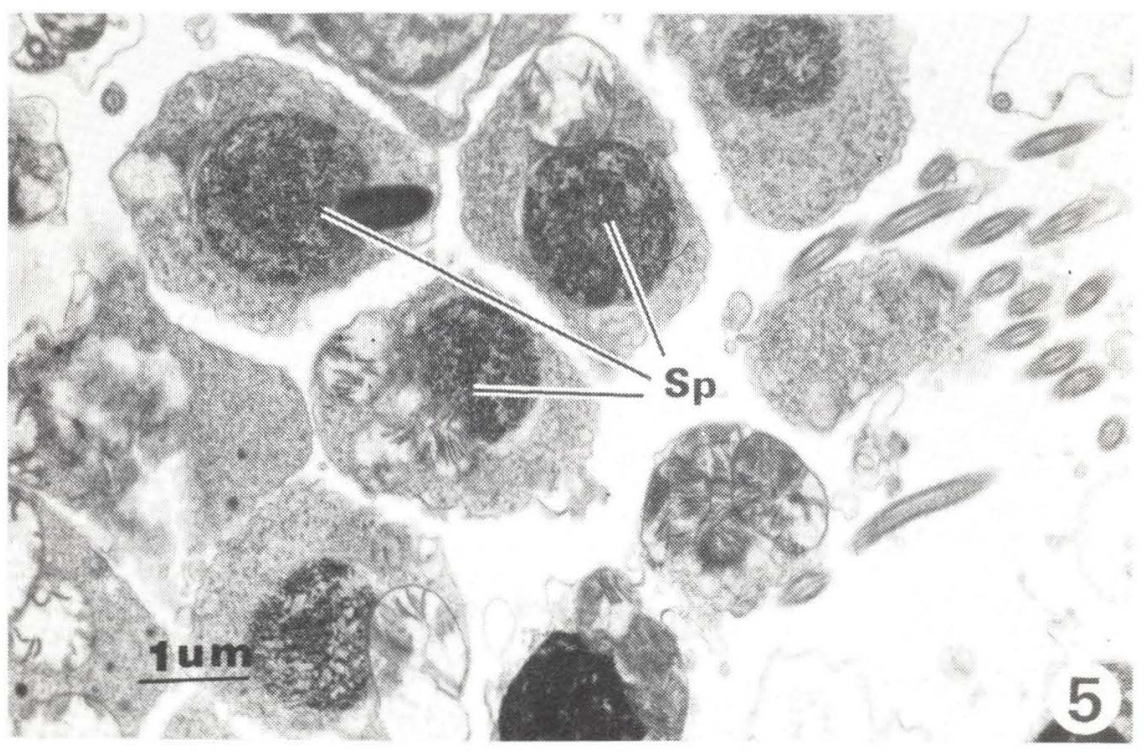

Fig. 5. Aspecto transversal de espermatozóides em fases de maturação (Sp.).

\section{DISCUSSÃO}

O espermatozóide de Donax striatus examinado é do tipo primitivo (FranZÉn 1983). Rouse e Jamieson (1987) propõe para o gênero Donax, morfologia e modo de fertilização. Os espermatozóides de $D$. sordidus e $D$. madagascariensis apresentam similaridades variando apenas como modificações nas dimensões (HODGSON et al. 1990), cujos achados não apresentam surpresas para KILBURN \& RIPPEY (1982). Para os espermatozóides do gênero Donax, subclasse Heterodonta, não existem modificações significativas para outros heterodontes (Popham 1974 a,b; Popham et al. 1974; Popham 1979; FranzÉn 1983; MAXWELl 1983). Outros achados apresentam suposições de que as estruturas espermáticas possam ser avaliadas como características de estudos taxonômicos (FrANZÉn 1970, 1983; Popham 1979; Hodgson \& BERNARD 1986).

O núcleo e a peça intermediária dos espermatozóides de Donax são tipicamente denominados de ect-aquasperm (ROUSE \& JAMIESON 1987). O acroso- 

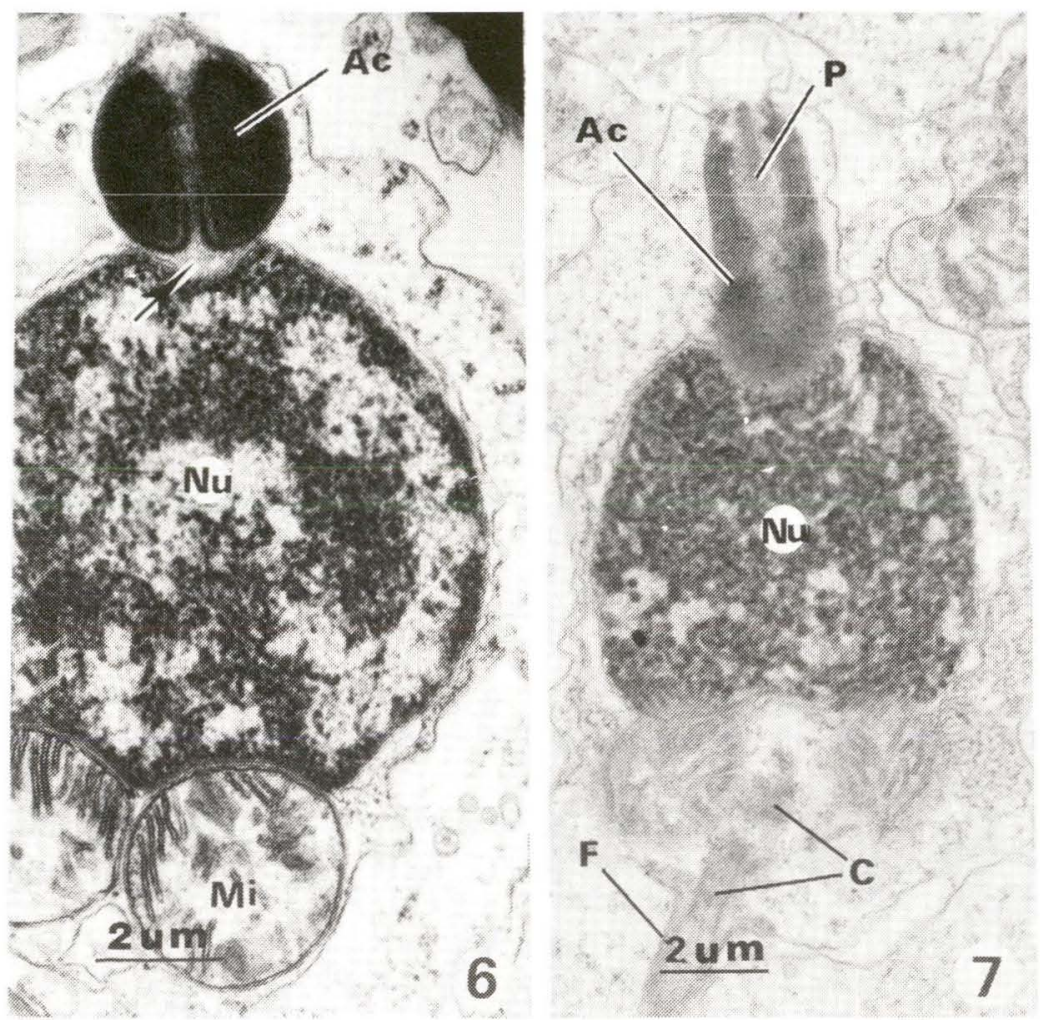

Figs 6-7. (6) Corte tangenciando espermatozóide em fase inicial de maturaçāo; (7) espermatozóide em fase final de maturação. Acrosoma (Ac), centriolo (C), flagelo (F), fossa acrosômica (seta), mitocôndria (Mi), núcleo (Nu), perfuratório (P).

ma pode ser diferenciado pela eletrodensidade e radiolucidez de regiões, fato característico de alguns bivalves (POPHAM 1974 a,b; HYLANDER \& SUMMERS 1977; FranzÉN 1986; MAXWEll 1983; HodgSON \& BERNARD 1986). Estas regiões de diferentes eletrodensidades provavelmente refletem funções do acrosoma durante a fertilização (PoPHAM 1974b; HYLANDER \& SuMMERS 1977). O conteúdo acrosomal tem sido descrito para outros moluscos (GALANGAU \& TUSET 1968; LONGO \& ANDERSON 1970; AZEVEDO 1981; SOUSA et al. 1989).

As mudanças estruturais ocorrem durante a espermatogênese e são similares para as descrições em outros invertebrados (ROOSEN-RUNGE 1977; ADIYODI \& ADIYODI 1983; HODGSON 1986), desde a condensação cromatínica nuclear até a formação acrosomal pelo complexo de Golgi. Trabalhos sobre a presença de glicogênio na peça intermediária de espermatozóide de moluscos são bem documentados (ANDERSON \& PERSONNE 1970; MAXWELl 1983).

Finalmente, alguns espermatozóides de $D$. madagascariensis apresentam defeitos da emergência da cauda no longo eixo do espermatozóide sem afetar a 
fecundidade do animal devido a produção baixa de espermatozóides $\left(10^{10}\right.$ por $\left.\mathrm{ml}\right)$ (Hodgson et al. 1990). Os autores evidenciaram que o Donax striatus é predado por um molusco gastrópoda, Natica marochiensish Gmelin, 1791, assim como, a região da gônada pode estar infestada por um tipo de platelminto que poderá levar a um estado de castração do animal.

AGRADECIMENTOS. A Profa Dra Yoko Wakabara da Universidade de São Paulo, pela identificação da espécie. Ao Sr. João Carvalheiro pelo serviço iconográfico. Trabalho parcialmente subsidiado pelo JNICT (Portugal), CNPq, UFPA e FCAP.

\section{REFERÊNCIAS BIBLIOGRÁFICAS}

ADIYODI,K.G. \& R.G. ADIYODI. 1983. Reproductive biology of Invertebrates. II. Spermatogenesis and Sperm Function. Chichester, John Wiley \& Sons.

Anderson, W.A. \& P. Personne. 1970. The localization of glycogen in the spermatozoa of various invertebrate and vertebrate species. J. cell. Byology, 44: 29-51.

ANSEll, A.D. 1983. The biology of the genus Donax, p.539-546. In: A. McLachlan \& T. Erasmus (eds). Sandy Beaches as Ecosystems. Junk, The Hague.

AzEvedo, C. 1981. The fine structure of the spermatozoa of Patella lusitanica (Gastropoda, Prosobranchia) with special reference to acrosome formation. J. Submicrosc. Cytol. 13: 47-56.

DE VILLIERS, G. 1975. Reproduction of the sand mussel Donax serra Roding. Investigational Report of the Sea Fisheries Branch South Africa 102: 1-33.

FrANZÉN, A. 1970. Phylogenetic aspects of the morphology of the spermatozoa and spermatogenesis, p.29-46. In: B. BACCETTI (ed.). Comparative Spermatology. New York, Academic Press.

- 1983. Ultrastructural studies of spermatozoa in three bivalve species with notes on envolution of elongated aperm nucleus in primitive spermatozoa. Gamete Research 7: 199-214.

Galangau, V. \& O. Tuzet. 1968. L acrosome d Octopus vulgaris Lmk.: Observations au microscope eletronique. Comptes Rendus De L Academie des Sciences, Paris, 2670: 1462-1467.

HodGson, A.N. 1986. Invertebrate spermatozoa: Structure and spermatogenesis. Archives of Andrology 17: 105-114.

Hodgson, A.N. \& R.T.F. BERnARD. 1986. Ultrastructure of the sperm and spermatogenis of three species of Mytilidae (Mollusca, Bivalvia). Gamete Research 15: 123-135.

Hodgson, A.N.; R.T.F. Bernard \& G. van Der Horst. 1990. Comparative spermatology of three species of Donax (Bivalvia) from South Africa. J. Moll. Stud. 56: 257-265.

HylandER, B.L. \& R.G. SUMmERS. 1977. An ultrastructural analysis of the gametes and early fertilization in two bivalve molluses Chama macerophylla 
and Spisula solidissima with special reference to gamete binding. Cell $\&$ Tissue Res. 182: 469-489.

KILbuRn, R. \& E. RIPPEY. 1982. Sea Shells of Southern Africa. South Africa, Macmillan, 248p.

LONGO, F.J. \& E.J. ANDERSON. 1970. Structural and cytochemical features of the sperm of the cephalopod Octopus bimaculatus. J. Ultrastruc. Res. 32: 94-106.

Matos, E.; P. Matos; E. Oliveira \& C. Azevedo. 1993. Aspectos morfológicos e ultraestruturais do espermatozóide de Ermitão Clibanarius vittatus Bosc, 1802 (Crustacea, Decapoda) do litoral norte do Brasil. Rev. bras. Ciênc. morfol. 10: 126-131.

MAXWELL, W.L. 1983. Mollusca, 275-319. In: K.G. AdIYODI \& R.G. AdIYODI (eds). Reproductive Biology of Invertebrates. V. II: Spermatogenesis and Sperm Function. Chichester, John Wiley \& Sons.

McLachlan, A. \& N. HaneKom. 1979. Aspects of the biology, ecology and seasonal fluctuations and biochemical composition of Donax serra in the east Cape. South African J. Zoology 14: 183-193.

MCLACHLAN, A. \& G. VAN DER HoRsT. 1979. Growth and production of two molluscs from an exposed sandy beach. South African J. Zoology 14: 194-201.

POPHAM, J.D. 1974a. Comparative morphometrics of the acrosomes of the sperms of "externally" and "internally" fertilizing sperms of the shipworms (Teredinidae, Bivalvia, Mollusca). Cell. Tissue Res. 150: 291-297.

- 1974b. The acrosome reaction in the sperm of the shipworm Bankia australia Calman (Bivalvia, Mollusca). Cell Tissue Res. 151: 93-101.

. 1979. Comparative spermatozoon morphology and bivalve phylogeny. Malacological Review 12: 1-20.

Popham, J.D.; M.R. DiCKSON \& C.K. GodDARD. 1974. Ultrastructural study of the mature gametes of two species of Bankia (Mollusca: Teredinidae). Austr. Jour. Zool. 22: 1-12.

RoOsen-Runge, E.C. 1977. The process of spermatogenesis in animals. Cambridge, Cambridge University Press.

Rouse, G. \& B.G.M. JAMIESON. 1987. An ultrastructural study of the spermatozoa of the polychaetes Euryhoe complanata (Amphinomidae), and Clymenella sp., and Micromaldane sp. (Maldanidae), with a definition of sperm types in relation to fertilization biology. J. Submicrosc. Cytol. 19: 573-584.

SousA, M.; L. CoRral \& C. AzEvEDo. 1989. Ultrastructural and cytochemical study of spermatogenesis in Scrobicularia plana (Mollusca, Bivalvia). Gamete Res. 24: 383-401.

Recebido em 19.IX.1994; aceito em 18.VI.1995. 